\title{
Research on Influences of Margin Trading on Liquidity and Volatility of Market
}

\author{
Di Gu \\ Antai College of Economics \& Management, Shanghai Jiao Tong University, 200030, China
}

Keywords: Margin trading, Liquidity, Volatility

\begin{abstract}
In essence, since the securities market joined the margin trading mechanism, it has achieved optimization and expansion for nearly five times. To a certain extent, the number of underlying stocks shows an unprecedented rise. Short selling is also on the right track in the current market and the transaction volume is also constantly improving. Facing the factors of the market turmoil, the paper analyses the influences of financing securities and financing transactions on liquidity and volatility of market. According to the relevant data, this paper constructs rationalization proposals to enhance the efficiency of China's financing securities trading.
\end{abstract}

\section{Introduction}

\subsection{Research Background and Significance}

From the present form, the financing securities, in essence, mainly show that the investors need to use the qualified securities companies to deposit the corresponding collateral, and under this effect, the financing buy or the selling of the margin is sold, the change of thinking is analyzed, which belongs to the category of business activities. Therefore, under the effect of margin trading, if we want to gain more profits, we need to analyze the transaction risk under the market effect. According to the characteristics of the securities market, margin trading can reduce the extra fluctuation of the market and promote healthy investment and development. Margin trading can also, to a certain extent, enhance the demand for capital and securities, enhance and activate market liquidity. We analyze the margin trading, margin trading and education financing in the market liquidity and volatility effect, provides a more robust way of sustainable development for the market.

\subsection{Research Route}

From 2010 to the present, the stock market has experienced expansion for five times, and the number of underlying stocks has been continuously improved. In the bull market in 2015, the margin trading in the Shanghai stock market jumped to 1 trillion and 480 billion. Therefore, if we want to use the financing transaction to improve the market volume, we need to improve the liquidity of the market and reduce the volatility which is divorced from the actual market.

\section{Influences Summary of Margin Trading on Liquidity and Volatility of Market}

\subsection{Influences Factors of Liquidity and Volatility of Market}

From the beginning of the market liquidity impact analysis, mainly reflects the ability of capital market liquidity, to a certain extent, also shows the good development trend of the market. In other words, the higher the liquidity of the market, the greater the volume, and does not produce large fluctuations, construction of the main description of the stock market width, depth, flexibility and timeliness. Therefore, from the factors of market liquidity, the design of financial products and the structure of the market are discussed. The three aspects of investors' decision making have shown the impact on market liquidity. From the influence factors of market volatility, the market volatility of the transaction process, affected by the field of internal and external factors, stock price and the par value 
is not equal, also appeared abnormal phenomenon called. The factors that affect market volatility are mainly three types: macro and micro factors, and other factors. Reasonable fluctuation is a reasonable response to market operation and is also the main reason for the loss of market operation and the damage of assets.

\subsection{Influences of Margin Trading on Market}

From the point of view of financing transactions, when a certain stock in the market is obviously low, it will be relatively rational to find stocks underestimated early. At this time, these rational investors will use financing transactions to buy large quantities of stocks. Financing will also inject large amounts of capital into the market. With the increase of market demand, to a certain extent, it also improves the liquidity of the market. Then, more and more people are buying, so the stock price will continue to rise. Investors in financing transactions will make delivery at this time, sell securities, return borrowed funds, and enhance market liquidity. Under the information trend of the high market, it will drive more investors to buy stocks and further enhance the market liquidity. Under the influence of high information, more people will join in the investment and further enhance the market liquidity. When the stock price rises, the demand for supply will decrease, and investors will have to pay for the return and further enhance the liquidity of the market.

\section{Empirical Analysis of Influences of Margin Trading on Liquidity and Volatility of Market}

\subsection{Hypothesis}

In essence, market liquidity is a process in which investors can buy and sell stocks quickly and execute transactions at lower cost. At the same time, it will also be affected by the price of trading stocks themselves. Moreover, the impact of margin trading on market liquidity can be explored through two points: financing and short selling. Therefore, in the market cycle alternating changes in the background, the margin for the market liquidity impact, the transaction will appear to improve the situation, later there will be a sharp decline. We can find that:

Hypothesis 1: when the volume of transactions increases significantly, the introduction of margin trading mechanism can enhance the liquidity of the market.

Hypothesis 2: when trading volume presents a marked decline, the introduction of margin trading mechanism can also enhance the liquidity of the market.

Hypothesis 3: when the price of stock market rises sharply, the introduction of margin trading mechanism can suppress market volatility.

Hypothesis 4: when the price of stock market drops sharply, the introduction of margin trading mechanism can suppress market volatility.

\subsection{Index Selection and Division}

We select to analyze the liquidity and volatility of S stock market here and to construct the capital margin balance the amount of change index and liquidity index, the volatility index for empirical inquiry.

(1) the amount of change in the construction of margin balance index, mainly through on the margin balance change measure, the t market margin balance compared with the previous one will show the change in t-1, using D (MP_SS) t show, the use of the RMB unit is the yuan.

(2) from the market liquidity index, we can find that the larger the transaction volume, the higher the liquidity. Therefore, we can make use of the combination of price and quantity in two aspects to reflect liquidity more directly. Indicators:

$$
\mathrm{LIQ}=\log \left(\mathrm{V}_{\mathrm{t}} / \mathrm{R}_{\mathrm{t}}\right)
$$

$V_{t}$ is the total daily turnover of the Shanghai stock index one hundred and eighty index. $R_{t}$, is the rate of return on the stock. So, it can be concluded:

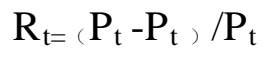


What $P_{t}$ shows is the opening price of stock $t$ days. $P_{t}$ shows the closing price of $t$ day. $t$ can be seen that the liquidity of the market is directly proportional to the amount of the transaction, but it has an inverse proportion to the rate of return.

From the perspective of the index of market fluctuation, we analyze:

$$
\mathrm{VOL}_{\mathrm{t}}=\left(\mathrm{P}_{\mathrm{t}}-\mathrm{P}_{\mathrm{t}}\right) /\left[\left(\mathrm{P}_{\mathrm{t}}+\mathrm{P}_{\mathrm{t}}\right) / 2\right]
$$

It can be seen that $\mathrm{P}_{\mathrm{t}}$ shows the highest price of the $\mathrm{T}$ Shanghai Post Shanghai Composite Index, of which Pt shows the highest low price of the Shanghai Composite Index after t days. Thus, select the Shanghai one hundred and eighty index, this way, further realize the calculation and analysis, can directly show the popularity of the market volatility, is a feasible implementation plan. The above data are derived from the database of Guotaian.

In the division of stages, with the continuous changes of capital market and the rise of Shanghai stock index, the vibration pattern has been developed to 2015. At this stage, there are 5000 points, and then a sharp decline, showing 3000 points. Therefore, in accordance with the expansion point of margin trading market, it can be divided into the following five expansions. Table 1 shows the details.

Table 1. Expansion time of margin trading market

\begin{tabular}{llr}
\hline List & Time & $\begin{array}{r}\text { underlying stock number } \\
\text { (two markets) }\end{array}$ \\
\hline The first time & 2011.12 .5 & 285 \\
The second time & 2013.1 .25 & 500 \\
The third time & 2013.9 .16 & 695 \\
The four time & 2014.9 .22 & 900 \\
The fifth time & 2016.12 .12 & 950 \\
\hline
\end{tabular}

\subsection{Empirical Test}

From the analysis of the stationary test point of view, for the two-time series regression test show the change trend. If the show is always change, so between the two sequences does not exist between the economy, this is the so-called spurious regression phenomenon.

Based on the stationary stage, intercept exist margin balance change index is shown in Figure 1. The stable stage balances change trend, Figure 2 shows the liquidity trends. It can be found that the flow index intercept exists, but the trend does not exist.

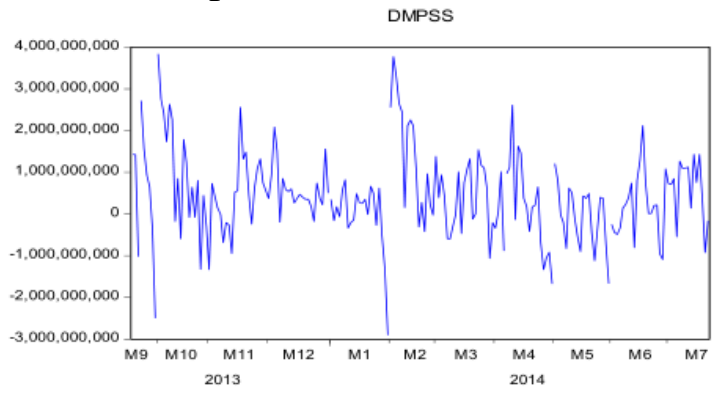

Figure 1

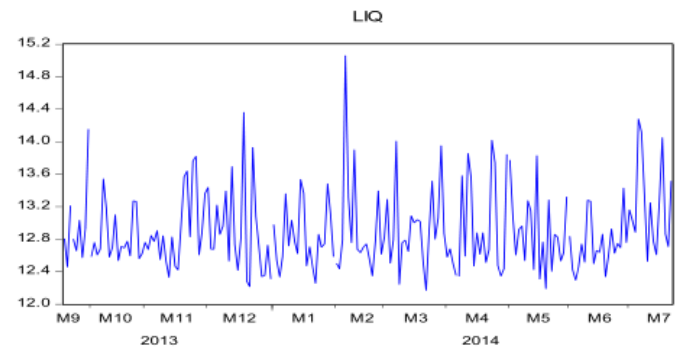

Figure 2

From the rising stage, there is a corresponding intercept item in the rising stage and the change of the balance amount, and the trend item does not exist. Refer to the Figure 3. The trend chart of the balance change in the rising stage, and Figure 4 shows the liquidity trend chart. In the rising stage, the intercepting term of liquidity index exists, and the trend item does not exist. 


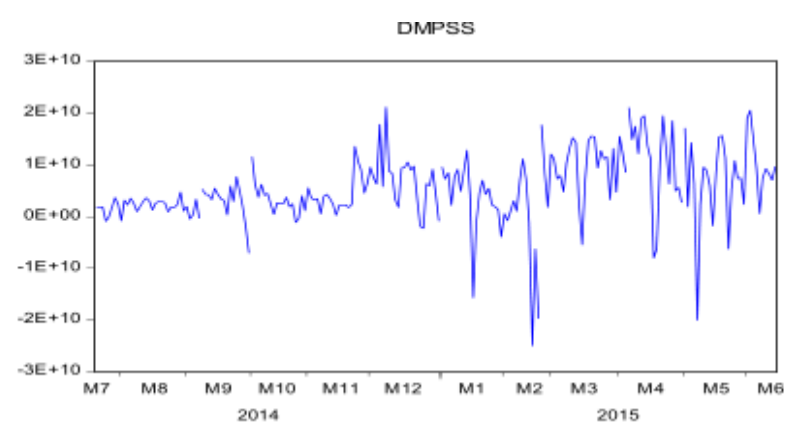

Figure 3

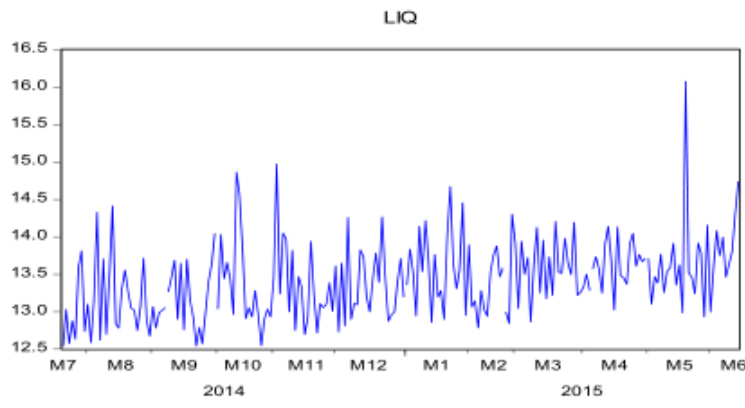

Figure 4

Table 2. Unit root test

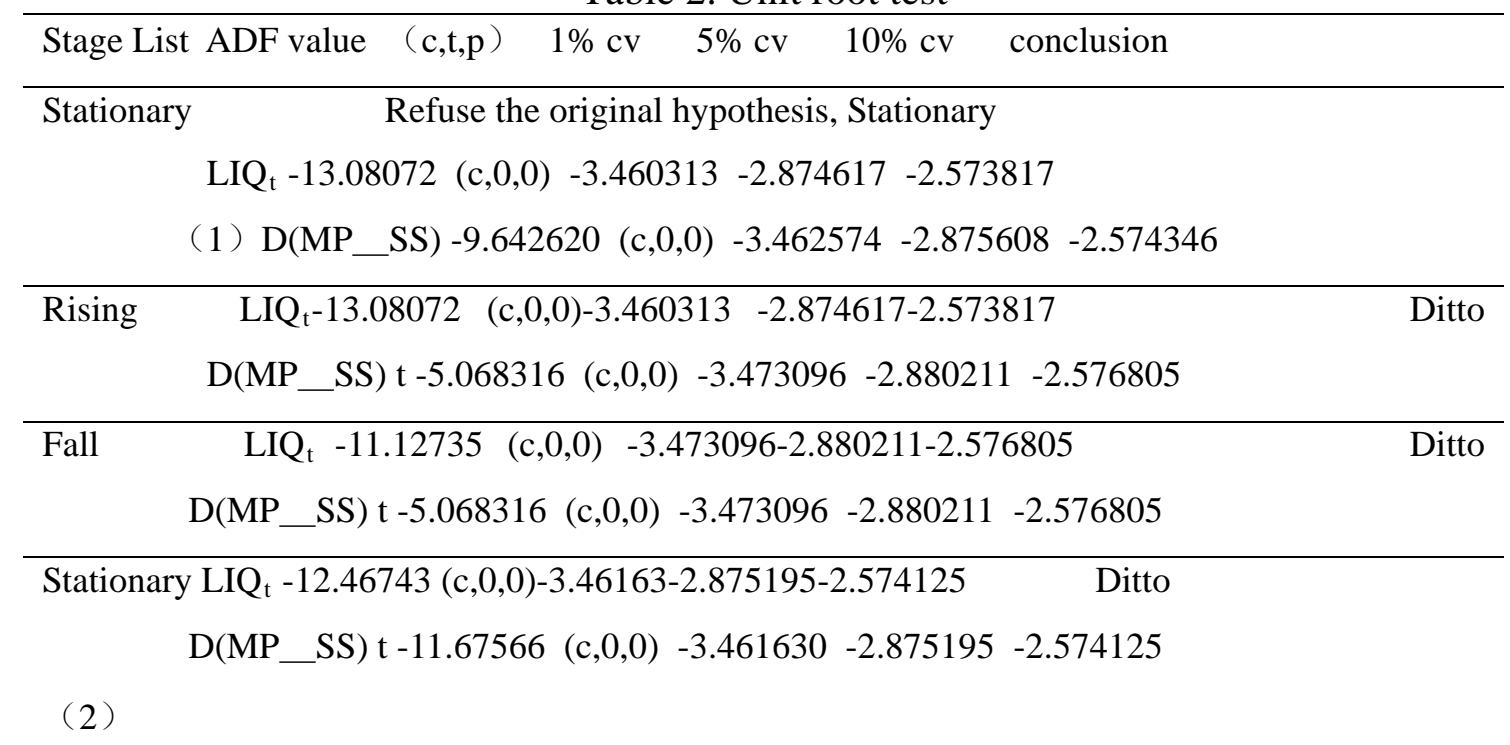

Note: cv stands for critical value

Based on the above, we can find that whether it is stationary stage one or two or rising stage or falling stage. There is no trend in margin and market liquidity.

Therefore, from the perspective of Grainger causality test, there will be different causality in different stages. From the perspective of impulse response analysis, the higher the liquidity, the greater the positive change of margin, and the faster the margin growth will be. Thus, the margin analysis of the impact of market volatility, mainly to show the decline stage, the SSE 180 index fell rapidly, investors began selling many stocks. The correlation with market liquidity declined, and Grainger test was not significant. So, suppose one conforms, if two is inconsistent. In the impact of market liquidity on margin trading, the activation of OTC and umbrella trusts can increase share prices and increase the volatility of premium stocks. Suppose four conforms, if three is not. In other words, joining the margin trading mechanism can improve market liquidity and curb market volatility. Empathy can be verified, when trading volume increased sharply, financing transactions and margin trading can enhance market liquidity, a decline in time, margin trading can inhibit the volatility of the market.

Therefore, first, under the situation of sharp increase in trading volume, margin trading can improve market liquidity to a certain extent. In other words, financing transactions contribute more to liquidity, margin trading can improve liquidity, but less contribution. Second, when the stock price rises rapidly, margin trading can restrain market volatility to a certain extent. In other words, financing transactions contribute more to liquidity restraining, but margin trading can inhibit liquidity, but the contribution is small. 


\section{Conclusions}

According to the above analysis, we can find that if we want to improve the margin trading mechanism, we need to do the following four points. First, strengthen the concept of investors, that is, strengthen the concept of short selling. Second, the cost of margin trading and the threshold of trading need to be appropriately lowered, increasing investor transaction costs and enhancing market activity. Third, pay attention to system construction, and actively absorb foreign experience, improve their own system, eliminate risks and strengthen market monitoring. Fourth, to build an effective margin system. Maintain leverage efficiency, and make scientific, rational and flexible use of stock market and economic environment. Raise the margin, activate the market and ensure the healthy development of the securities market.

\section{References}

[1] Wang Chaoyang, Wang Zhenxia. Price Limit, Margin Trading, and Stock Price Volatility: A Comparative Study between A-shares and H-shares [J]. Economic Research Journal, 2017(4): 151-165.

[2] Xiao Hao, Kong Aiguo. A Study on the Mechanism of the Impact of the Securities Margin Trading on the Fluctuations of the Special Nature of the Stock Price: A Test Based on the Difference-in-Difference Model [J]. Management World, 2014(8): 30-43+187-188.

[3] Chen Haiqiang, Fan Yunfei. The Impact of the Launch of Margin Trading and Short Selling on Chinese Stock Market Volatility : Evidence from A Panel-Data Policy Evaluation Approach [J]. Journal of Financial Research, 2015(6): 159-172.

[4] Liu Shancun, Cheng Bohao, Yang Zhuo, et al. Research on the Impact of Margin Trading on Stock Price Volatility [J]. Journal of Beijing Jiaotong University (Social Sciences Edition), 2018, 17(2): 61-70. 